\title{
BEHAVIOURAL FINANCE - A REVIEW PAPER
}

KEY WORDS: Behavioural finance, traditional finance, Modern finance, behavioural economics.

\section{Mohit Fogaat*}

\section{Sangeetha} Sharma
Research Scholar, Department of Commerce, Central University of Haryana, Mahendragarh, Haryana. *Corresponding Author

Research Scholar, Department of Commerce, Central University of Haryana, Mahendragarh, Haryana.

F The current research examines the evolution of behavioural finance over the span of financial history. It contains the earliest records of stock market behaviour oddities recorded by researchers. Traditional finance is discussed first, followed by an examination of traditional ideas in instances when they are judged inadequate. The study then discusses 근 importance of behavioural finance and its key role in creating a connection between real-world scenarios and classical assumptions.

\section{INTRODUCTION-}

Behavioural finance is the mixture of conventional economics and finance with thinking and decision-making process and it try to explain how investors thoroughly errors in judgement or mental mistake[1]. Behavioural finance talks about how individual's behaviour influence from behavioural finance biases when they are making financial decisions or investing decisions. In the subject of economics and finance, behavioural finance is a dynamic and rapidly evolving field. Beginning in the early 1970s, Daniel Kahneman and Amos Tversky pioneered the behavioural finance revolution[2]. In recent years, interest in the combination of psychology and economics known as "behavioural economics" has grown, and as with many seemingly sudden positive stories, this one has been in the works for quite some time[3]. Overconfident investors exaggerate the accuracy of their understanding about a financial security's pricing, and they exaggerate the likelihood that their own evaluations of the security's price are more correct than someone else' opinions[4]. People do not always act rationally, and while deviations from rationality can be random, they are frequently systematic, as evidenced by the fact that significantly more people overestimate rather than underestimate their driving ability[5]. As we know that human posses' feelings which can affect their choices. Decisions made by emotionally lead us to irrationality and it can lead us to big crash in stock market. There are two school thought in behavioural finance one is traditional finance and another is modern finance. Traditional finance assumes that all market participants are fully rational and they not need to any suggestion or recommendation from others. In Modern finance, we talk about that financial decision is affected by psychological factor and investor makes mistake when they are making financial decision. The concept of a rational investor dominant in behavioural economics more than 50 years. A rational man expected to be cost-effective, rationality in decision making process, expert in calculating the chances of each substitutes and choose the best alternative which gives the best utility at low cost[2]. A myopic investor is one who interprets prior outcomes narrowly and constantly evaluates his profits and losses. Narrow decision-making and narrow outcome-making tend to go along, and the mix of these characteristics constitutes a myopic investor[6]. Investors trade quite so much, purchase or sell at the wrong moment, allow emotions to override rationality, and underestimate probability due to inefficiencies in applying rules[7].

Traditional economic and finance philosophies made on the hypothesize of rational human behaviour entitlement that families maximise their utility function over their life cycle[8]. Recent unprecedented event COVID-19 where all over the world peoples suffering from deadly pandemic and financial market of many countries was badly affected. There is no way to forecast a 'black swan' occurrence, but it is conceivable to compare earlier markets as they navigate these important anomalies, because everything in our world is a fresh news event that follows a predictable pattern[9].

The epidemic of COVID-19 has an unusual impact on the world financial market, and as a result of the global market interruptions, India's financial market has also responded to the pandemic, with market turmoil[10]. Because of the unpredictability and volatility in the stock and commodities markets, we decided to investigate the influence of COVID-19 on the Indian commodity and stock markets, as well as compare the volatility of stock markets in other South Asian countries[11]. No one can predict how long COVID-19 will have an impact on the economy, which is causing issues in evaluating both medium-term and long-term growth rates. With a lower projected growth (as the future is did work out), the subject Company has become less appealing to prospective buyers as the inconsistencies that may affect the company grow over time [12]. When the number of individuals trying to sell a stock outnumbers the number of individuals wanting to acquire it (there is more supply than demand for that specific stock), the stock price drops, and the presence of anomalies has been widely acknowledged in financial markets over the past 2 decades[13]. Many behavioural finance biases show their presence in this pandemic where investors started making mistake. Many behavioural finance biases occurred in this pandemic like risk-aversion, herd behaviour, overconfidence, illusion of control, overreaction and self-attribution etc. These biases directly affect investors choices of investment. As we know that a normal investor hesitates to taking risk and this pandemic makes investor more sophisticated to take risk because most of investor lost their strong portfolio investment and economy of nations came down to negative GDP growth rate from their strong GDP growth rate.

We don't live in such world where market is informationally efficient. The market mostly inefficient because after 1960 some research work showed us that investors are not fully rational and they make mistake in financial decision process because of behavioural finance biases. Thus, investors have to be understood the such market anomalies' which directly affect investment decision.

Behavioural finance is emerging topic for research where researcher can investigate about new concept of behavioural finance biases and recommend to investors for better investment decisions. Behavioural experts understand the different biases of behavioural finance and suggest to the investors to avoid making mistakes when they are making financial decision. 


\section{Traditional finance versus Modern Finance or behavioural}

\section{finance -}

Traditional finance holds the concept that investors are fully rational and they have fully capable for making their investment decision. In the traditional finance it is assumed that market and investors are perfectly rational and they truly care about utilitarian features. Individual are sometimes referred to be "rational expectations wealth maximizers," which indicates they establish unbiased aspirations and then buy and sell assets at values that they believe will enhance their holdings' future value [1]. It is assumed that investor have fully discipline in investing decision and they are not disordered by cognitive errors or information processing mistakes. The efficient market hypothesis and modern portfolio theory are at the heart of conventional finance. In 1952, Harry Markowitz pioneered modern portfolio theory.

Modern portfolio theory is concerned with the anticipated return of a stock or a portfolio, as well as its standard deviation and connection with other securities in the holdings[14]. Another important notion in conventional finance is the Efficient Market Hypothesis. According to EMH, all proof has already been represented in a security's level or market rate, and the stock or bond's current price represents its fair value[14]. Proponents argue that when securities are at their fair value, active dealers or professional investors cannot produce larger returns over time that outperform the market.

As a result, they argue that rather than attempting to make a lot of money, investors might as well just own the overall market.

\section{Traditional behavioural theories [15]}

In traditional theoretical approaches, John Stuart Mill was the first to establish the notion of the "Economic Man or homo economicus," in 1844. In 1954, Bernoulli proposed the "Bernoulli Hypothesis." In 1944, Von Neumann and Morgenstern also performed a utility function. Harry Markowitz published the "Markowitz portfolio theory" in 1952. "Capital Asset Pricing Model (CAPM)" was developed by Treynor (1962), Sharpe (1964), Lintner (1965), and Jan Mossin (1966). Eugene Fama presented "Efficient market theory" in 1970.

\section{Modern or behavioural finance -}

Modern finance holds the concept that investors are not fully rational. An individual possesses the emotional and psychological factor in their mind when they are making financial decisions. According to traditional finance each investor is fully rational but in reality, if each investor is fully rational then we don't have any market crash, any market anomalies, market bubbles and market overreaction or underreaction. Behavioral finance claims that certain aspects of asset pricing are better described as departures from core value, but that these deviations are driven by the presence of non-rational investors[16].

Evidence is accumulating that the CAPM, the market equilibrium model used in traditional finance to determine risk and anticipated returns, is not a reliable representation of reality[17]. An individual investor tends to make mistake and it leads market disruptions or big crashes in market.

Daniel Kahneman and Amos Tversky these two authors who brought the concept of behavioural finance in early 1970 . They also known for father of behavioural finance or economies. They published around 200 research paper regarding behavioural finance. Daniel Kahneman received Nobel Prize for his contribution in behavioural finance. Daniel Kahneman gave "Prospect theory" which provided basic groundwork to the field of behavioural finance. In comparison to the expected utility theory, they established a psychologically more accurate portrayal of decision making. People value losses and gains inversely, according to this notion, and will make decisions based on perceived gains rather than perceived losses[18]. Prospect theory is inspired by the fact that, in practice, decision makers violate both utility and probability rational thought hypotheses, and these breaches are merged into accumulated prospect theory as a non-linear utility function and a non-linear probability weighting operate effectively, which are advancements over the initial suggestion to confront infractions of random walk dominance limitations[19].

Another foundation of prospect theory is the Value Function. In anticipated utility theory, the value function varies from the utility function due to a frame of reference for by intuitive understanding of individual desires. The slope of the utility function in value function continues to climb for income level underneath the reference point and lower for income level after the reference point, but the utility function in anticipated utility theory is concave negative for all levels of income. As a result, each person chooses his or her own comparative point. At income level underneath this reference point, investors take risks; however, at income level further than this reference point, the value function is negative, as classic theories forecast, and investors are risk averse.

In a nutshell, Prospect Theory defines how people assess profit and loss. Editing and Evaluation are two distinct cognitive processes in this approach. During the Editing step, the investor ranks the options using a simple "Thumb Rule," as opposed to an elaborate algorithm.

A time reference is applied to compute gains and losses and to express loss aversion throughout the assessment process. A value function passing throughout this starting point and providing a "Value" to every good or negative result is S formed and asymmetrical[20]. The S-shaped value represented in the prospect theory is its most important component.

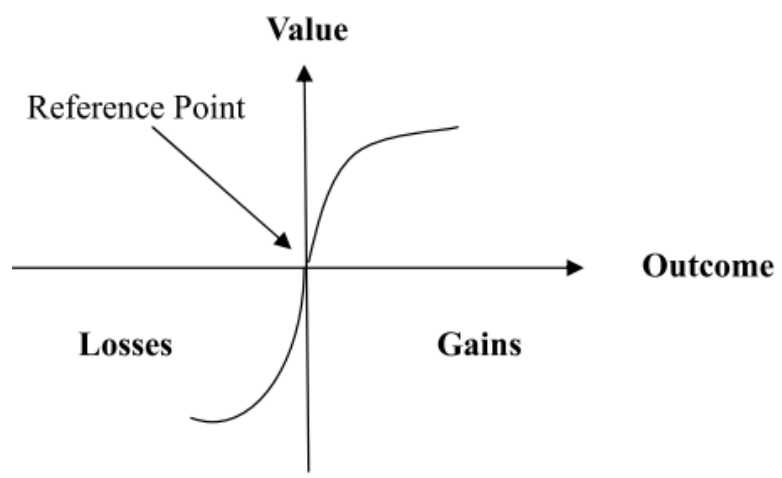

Figure - 1 Prospect Theory Value function, Source - [20]

\section{Modern behavioural theories [15]}

In 1955, Herbert Simon proposed "Models of limited rationality" in current behavioural theories. The "Theory of Cognitive Dissonance" was published in 1956 by Festinger, Riecken, and Schachter. Tversky and Kahneman published "Introduced heuristic biases: availability representativeness, anchoring, and adjustment" in 1973 and 1974. "The prospect theory" and "Introduced loss aversion bias" were both published by Tversky and Kahneman in 1979. They also "introduced framing bias" in 1981. Richard Thaler coined the phrase "introduced mental accounting bias" in 1985. In 1985, De Bondt and Thaler published "Theory of Overreaction in Stock Markets." In 1998, Barberis, Shleifer, and Vishny proposed the "Investor sentiment model for stock price underreaction and overreaction." Meri Statman proposed the concepts of "behavioural asset pricing theory and behavioural portfolio theory" in 1999. "Linkage of behavioural finance with efficient market theory to establish that stock markets are inefficient," says Andrei Shleifer. "Incorporation of prospect theory in asset pricing" was presented by Barberis, Huang, and Santos in 2001. 
"Importance of behavioural finance and its emphasis on departure from 'homo economicus' or traditional paradigm to more realistic paradigm," Hubert Fromlet wrote in 2001. Grinblatt and Keloharju published their paper "Role of Behavioral variables in influencing trading behaviour" in 2001. Barberis and Thaler published "Survey of Behavioral finance" in 2003. "Effect of behavioural biases on stock prices and the price reversal for biased investors is faster than for unbiased ones," Coval and Shumway found in 2006. Avanindhar Subrahmanyam discovered the "Normative implications of behavioural finance on individual investors and CEOs" in 2008. Richard Thaler discovered "Impact of mental accounting on consumer decision behaviour" in 2008. "Comparison the behavioural and traditional finance method in understanding market inefficiencies," by Rober Bloomfield, was published in 2010. "Practical implications of behavioural finance and investor feelings in value investing," according to Parag Parikh, was discovered in 2011 . Uzar and Akkaya published a paper in 2013 that "explores the emergence of behavioural finance from traditional finance."

\section{CONCLUSION -}

Behavioural finance is the study of individual behavior and its relevance in the investment judgment process. As we all know, this notion is developing, and it will be extremely beneficial to investors if they detect and eradicate any behavioural biases in order to make a fair selection. Behavioural finance challenges all previous ideas and introduces a novel paradigm in which investor behaviour has a direct impact on investment decisions. Individuals are compelled to make poor decisions as a result of investor behaviour. These unfavorable circumstances must be addressed since they have a negative influence on the financial situation of investors. They also have an impact on the country's economic situation. These safeguards can only be achieved if all behavioural experts are more aware of their own psychological knowledge and behavioural finance prejudices. Finally, we may state that in today's society, more experimental study in behavioural finance is essential.

\section{REFERENCES}

[1] R. J. Fuller, "Behavioral Finance and the Sources of Alpha," J. Pension Plan Invest., vol. 2, no.3,pp.291-, 1998.

[2] I. Alsedrah and N. Ahmad, "Behavioral finance:The missing piece in modern finance," Researchgate.Net, no. October, pp. 978-979, 2014, [Online]. Available:www.globalbizresearch.org.

[3] R.H.Thaler,"Behavioral economics: Past, present, and future," Rev. Econ. Inst., vol.20,no.38,pp.9-43,2018, doi: 10.18601/01245996.v20n38.02.

[4] B. M. Barber and T. Odean, "Boys will be boys: Gender, overconfidence, and common stock investment," Q. J. Econ., vol. 116, no. 1, pp. 261-292, 2001, doi: $10.1162 / 003355301556400$

[5] B. M. Barber and T. Odean, "The Courage of Misguided Convictions," Financ. Anal.J.,vol.55, no.6,pp.41-55, 1999, doi:10.2469/faj.v55.n6.2313.

[6] R. H. Thaler, A. Tversky, D. Kahneman, and A. Schwartz, "The effect of myopia and loss aversion on risk taking: An experimental test," Q.J.Econ., vol. 112, no. 2,pp.646-661, 1997, doi: 10.1162/003355397555226.

[7] D. Upadhyay and S. Paresh, "A Study on Behavioral Finance in Investment Decisions of Investors in Ahmedabad," Int. J. Nov. Res. Dev., vol. 4, no. 7, pp. 103-114,2019.

[8] K. K. Ingale and R. A. Paluri, "Financial literacy and financial behaviour: a bibliometric analysis,"Rev.Behav.Financ.,2020,doi: 10.1108/RBF-06-2020-0141.

[9] A. Dhillon and D.V.Tyagi, "Impact of COVID-19 On Indian Stock Market," Ann. Trop.Med.Public Heal., vol.23, no. 17,2020, doi: 10.36295/asro.2020.232027.

[10] D. Bora and D. Basistha, "The outbreak of COVID-19 pandemic and its impact on stock market volatility: Evidence from a worst-affected economy," J.Public Aff.,vol.21,no. 4,pp. 1-23,2021, doi: 10.1002/pa.2623.

[11] F. Ahmed, A. A. Syed, M. A. Kamal, M. de las N. López-garcía, J. P. Ramos- requena, and S. Gupta, "Assessing the impact of COVID- 19 pandemic on the stock and commodity markets performance and sustainability: A comparative analysis of south asian countries," Sustain., vol. 13, no. 10,2021, doi: 10.3390/sul3105669.

[12] H. Vikram Arora, "Impact of Covid 19 on the Indian Stock Market," J. Univ. Shanghai Sci. Technol., vol. 23, no. 07, pp. 1085-1090, 2021 , doi: 10.51201/jusst/21/07276.

[13] M. Sahoo,"COVID-19 impact on stock market:Evidence from the Indian stock market,"J.Public Aff., vol.21, no. 4,pp. 1-13,2021, doi: 10.1002/pa.2621.

[14] M. Statman, "What Is Behavioral Finance?," Handb. Financ., pp. 1-9, 2008, doi: 10.1002/9780470404324.hof002009.

[15] S. Kapoor and J.M. Prosad,"Behavioural Finance:A Review," Procedia Comput. Sci.,vol.122, pp.50-54,2017, doi: 10.1016/j.procs.2017.11.340.

[16] N. Barberis and R. Thaler, "Nber Working Paper Series a Survey of Behavioral Finance," NBER Work. Pap. Ser. , pp. 2-67, 2002, [Online]. Available: http://www.nber.org/papers/w9222

[17] M. Statman, "Behavioral Finance versus Standard Finance," AIMR Conf. Proc., vol. 1995, no. 7,pp. 14-22, 1995, doi: 10.2469/cp.v1995.n7.4

[18] M.Studies,"FINANCIALMARKET :The sis Doctor of Philosophy (Ph.D) Under the Supervision of (Associate Professor) Department of Business and Financial Studies Faculty of Commerce and Management Studies Department of Business and Financial Studi,"vol. 190006,2016.

[19] A. J. Keith, "Operational Decision Making under Uncertainty: Inferential, Sequential, and Adversarial Approaches,"p. 293,2019.

[20] S.R.I.C.Saraswathi andV.M.Vidyalaya,"'Behavioral Finance - a Special Study on Investor Psychology,"'p.2015,2015. 